\title{
Aspectos epidemiológicos do câncer cervical
}

\author{
Epidemiological aspects of cervical cancer
}

\section{Antonio Aleixo Neto*}

\begin{abstract}
ALELXO NETO, A. Aspectos epidemiológicos do câncer cervical. Rev. Saúde públ., S. Paulo, 25: 326-33, 1991. Foi efetuada revisão dos aspectos epidemiológicos do câncer cervical, um dos mais frequientes em mulheres de países em desenvolvimento. No Brasil a incidência varia de 23,7/100.000, em Porto Alegre, a 83,2/100.000, em Recife. Nos Estados Unidos a incidência em 1978 foi de $6,8 / 100.000$ entre as mulheres brancas e de 14,7/100.000 entre as negras. Várias observações sugerem a hipótese de que o câncer cervical esteja relacionado com algum aspecto da atividade sexual, possivelmente algum agente transmitido por via venérea. As evidências têm implicado o papilomavirus humano (HPV) como o principal agente etiológico deste câncer. Vários trabalhos foram analisados quanto à validade desta hipótese etiológica, mostrando que há uma relação entre HPV e o câncer cervical. Foram analisados os fatores de risco mais conhecidos, tais como o comportamento sexual, o tabagismo e a contracepção, diante das várias possibilidades etiológicas existentes.
\end{abstract}

Descritores: Neoplasias do colo uterino, epidemiologia. Vírus do papiloma. Fatores de risco.

\section{Introdução}

Com uma incidência em todo o mundo de cerca de meio milhão de casos por ano - principalmente em países em desenvolvimento - o câncer cervical permanece como um dos mais importantes e danosos cânceres da mulher.

Existem dois tipos histológicos básicos: o epitermóide, o qual surge predominantemente na junção escamo-colunar $\mathrm{e}, \mathrm{o}$ adenocarcinoma, o qual surge no epitélio glandular do endocervix. A relação de 20:1 entre o primeiro e o segundo tipo é benéfico para as pacientes, uma vez que o tipo epidermóide é mais fácil de ser localizado pela colposcopia, assim como de se obter células através de um esfregaço comum.

Outro aspecto importante no câncer do colo uterino é a existência de uma lesão precursora das lesర̃es invasivas: o carcinoma "in situ". Neste estágio, as alterações histológicas estão limitadas à superfície epitelial e o tratamento cirúrgico é curativo em 100\% das vezes.

Estes e outros fatos clínicos são por demais conhecidos, no entanto, vários aspectos ligados principalmente à etiologia e aos fatores de risco têm sido objeto de diversos estudos e novos achados têm surgido constantemente - mas de forma dispersa - trazendo muitas vezes confusão aos

\footnotetext{
* Departamento de Ginecologia e Obstetrícia da Faculdade de Medicina da Universidade Federal de Minas Gerais - Belo Horizonte - Minas Gerais, MG - Brasil.
}

Separatas/Reprints:A. Aleixo Neto - Rua Nicarágua, 108/102-A Sion - 30330-Belo Horizonte, MG - Brasil. médicos ginecologistas.

Desta forma, o objetivo do presente trabalho foi fazer uma revisão sobre vários aspectos epidemiológicos desse tipo de câncer, tais como: a distribuição, as curvas de incidência conforme a idade no Brasil, e - principalmente - um amplo apanhado das hipóteses etiológicas, dos fatores de risco e as perspectivas futuras de pesquisa nesse campo.

\section{Incidência}

A despeito das primeiras observações efetuadas por Rigoni Stern em 1841 sobre a incidência, distribuição e possiveis fatores causais do carcinoma no colo do útero (prevalência mais alta em mulheres casadas do que em solteiras, incidência extremamente rara em freiras), a estatística descritiva deste câncer ficou prejudicado até os anos 40 , quando foi iniciado o registro separado do câncer do colo e do corpo do útero, os quais até então eram considerados em conjunto.

De um modo geral, a incidência é muito mais alta em países em desenvolvimento, especialmente na América Latina. O Brasil é considerado uma das áreas de alto risco para o carcinoma cervical, como se pode verificar em publicações da $\mathrm{WHO}^{28}$ que fornecem dados de quatro cidades brasileiras: São Paulo $(1969,1973,1978)$, Recife (1978), Fortaleza (1978) e Porto Alegre (1982).

Como se pode ver na Figura 1, a incidência ajustada pela idade do câncer cervical entre as quatro cidades varia de taxas relativamente baixas em Porto Alegre $(23,7 / 100.000)$ até as altas taxas de Recife (83,2/100.000). 


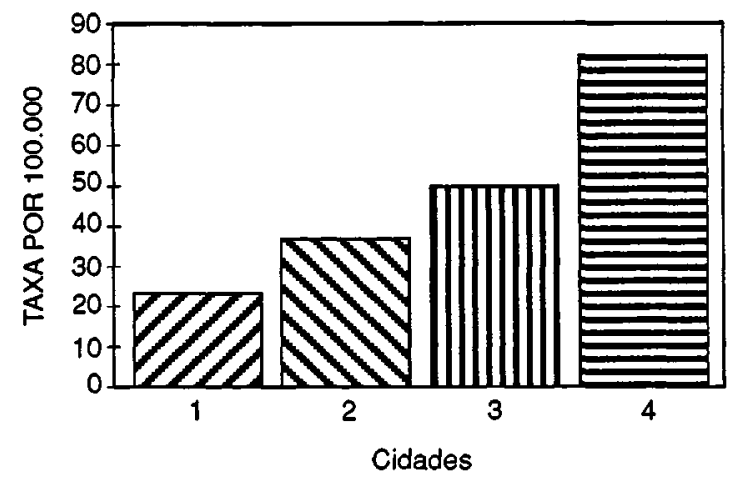

$$
\begin{aligned}
& \text { 1- Porto Alegre } \\
& 2 \text { - São Paulo } \\
& \text { 3 - Fortaleza } \\
& 4 \text { - Recife }
\end{aligned}
$$

Figura 1. Incidência do câncer cervical, ajustada à idade, em quatro cidades, Brasil, 1978.

Fonte: World Health Organization ${ }^{28}$

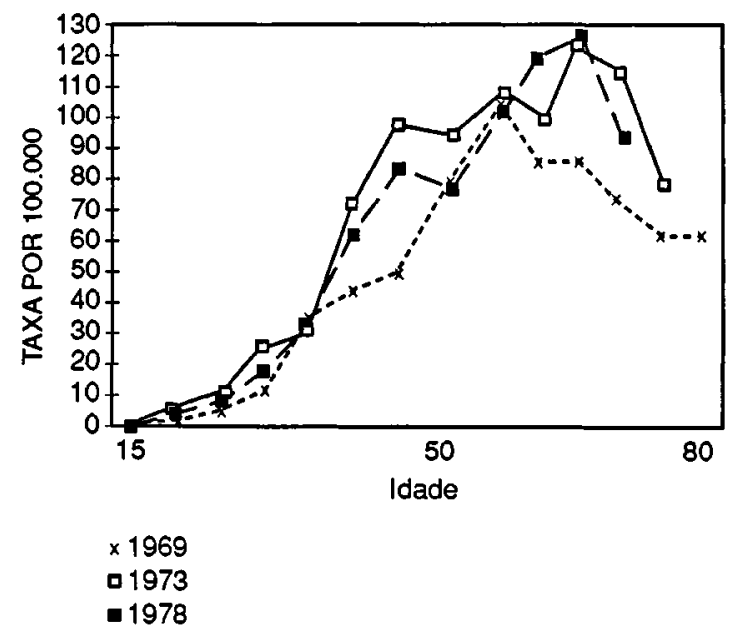

Figura 2. Incidência do câncer cervical, conforme à idade, Sáo Paulo, Brasil.

Fonte: World Health Organization ${ }^{28}$

A Figura 2 mostra as tendências das curvas conforme a idade, em São Paulo, entre 1969 e 1978. Pode-se observar crescimento acentuado em torno dos 25 anos, em todas as curvas, e então diferentes inclinações. O grupo de 1969 tem um pico ao redor dos 55 anos e depois um gradual declínio. $O$ grupo de 1973 mostra antes um "plateau" do que um pico, entre os 45 e 65 anos. Finalmente, o grupo de 1973 mostra um pico de incidência pelos 65 anos de idade e depois uma queda acentuada. Pela incidência ajustada pela idade, mostrada na Figura 3, pode-se observar um ligeiro declínio em São Paulo, entre 1973 e 1978.

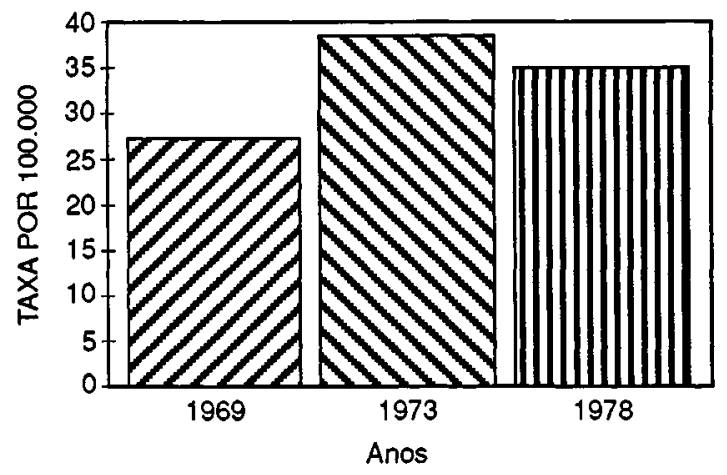

Fonte: World Health Organization ${ }^{28}$

Figura 3. Incidência do câncer cervical, ajustada à idade, São Paulo, Brasil.

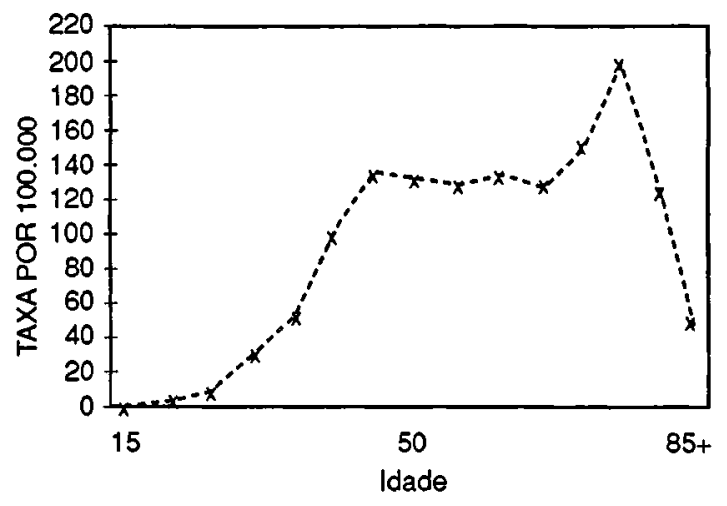

Figura 4. Incidência do câncer cervical, conforme à idade, Fortaleza, Brasil, 1978.

Fonte: World Health Organization ${ }^{28}$

As Figuras 4, 5 e 6 mostram três diferentes padrões em Fortaleza, Recife e Porto Alegre. Além das diferenças nas taxas de incidência por idade específica, entre as três cidades, pode-se observar que a curva de Fortaleza apresenta um pico inclinado ao 75 anos de idade, depois de um padrão de "plateau" desde os 45 anos.

A curva de Recife apresenta um "plateau" irregular entre 45 e 80 anos de idade e, finalmente, Porto Alegre mostra um crescimento gradual após os 20 anos e uma ligeira queda pelos 50 anos.

Em outros países os dados podem variar. Nos Estados Unidos, por exemplo, verifica-se uma significativa diferença na incidência deste câncer entre mulheres brancas e negras. No estado de Connecticut, por exemplo, a incidência ajustada pela idade, em 1978, foi de 6,8/100.000 entre as brancas e $14,7 / 100.000$ entre as negras. 


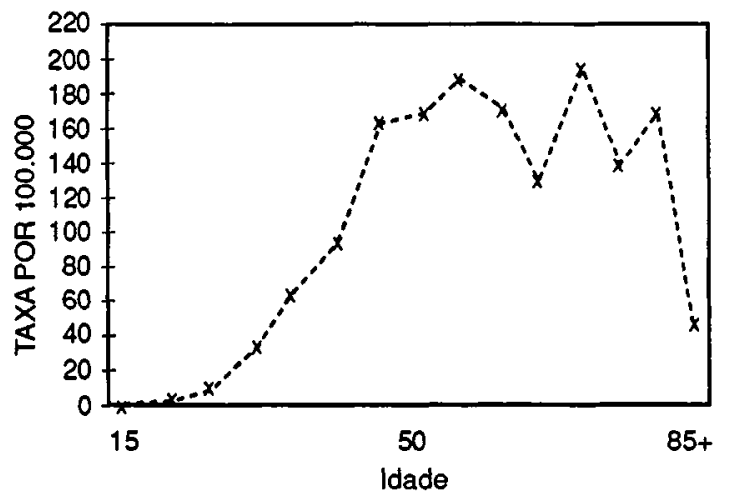

Figura 5. Incidência do câncer cervical, conforme à idade, Recife, Brasil, 1978.

Fonte: World Health Organization ${ }^{28}$

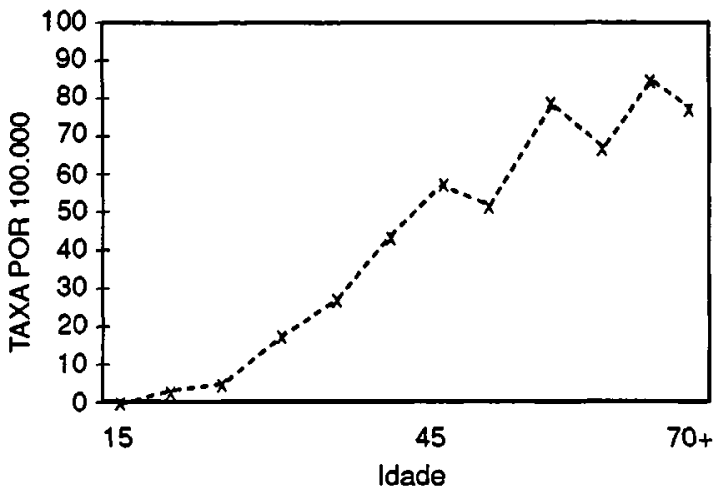

Figura 6. Incidência do câncer cervical, conforme à idade, Porto Alegre, Brasil, 1982.

Fonte: World Health Organization ${ }^{28}$

Outro detalhe importante nos Estados Unidos é que o verdadeiro denominador para o câncer cervical deveria ser, na realidade, o número de mulheres com útero ou não histerectomizadas. Cramer ${ }^{6}$ (1982) observou que a prevalência de mulheres com histerectomias é muito alto nos EUA e que isto poderia causar uma subestimação do risco em mulheres que têm o útero.

Enquanto que, em quase todo o mundo tem sido observado uma diminuição da incidência do câncer invasivo do colo. Peto ${ }^{19}$ (1986) relatou um aumento de 4 vezes, nos últimos 20 anos, entre as mulheres jovens britânicas.

A curva de incidência por idade das lesões préclínicas é muito útil para analisar o período de latência e outros achados. A Figura 7, de dados da Suécia - onde existe uma excelente taxa de notificação para o carcinoma "in situ" (Peto $\left.{ }^{19}, 1986\right)$ - mostra que o pico ocorre 20-30 anos mais cedo do que o câncer

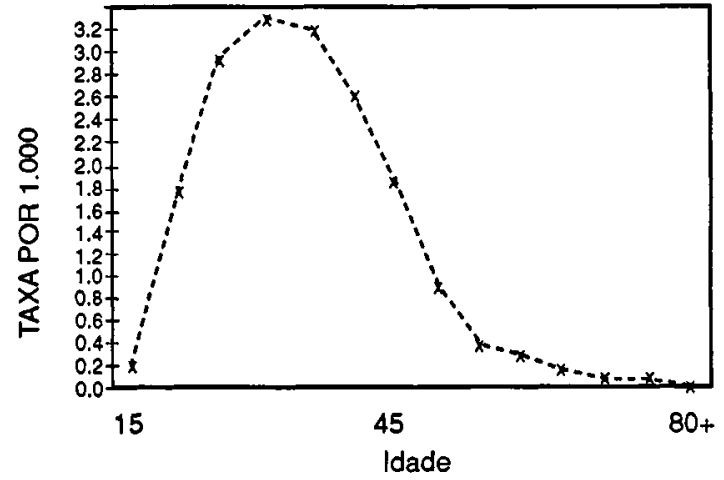

Figura 7. Carcinoma "in situ": incidência por idade na Suécia, 1969.

Fonte: World Health Organization ${ }^{28}$

invasivo, ou seja, o período de latência. A mesma Figura também mostra que a maior parte dos casos de carcinoma "in situ" ocorre na idade reprodutiva, ou seja, entre 15 e 50 anos de idade.

\section{Hipóteses etiológicas}

Em geral, o carcinoma do colo uterino mostra incidência mais alta em populações urbanas que nas rurais, em classes sociais mais baixas do que nas classes mais altas, em paises em desenvolvimento do que nos desenvolvidos, em mulheres negras americanas do que em brancas, em não virgens do que em virgens, em viúvas e divorciadas do que em casadas, em multiparas do que em primíparas, em mulheres cuja primeira gravidez ocorreu em idade jovem do que naquelas que tiveram a primeira gravidez em idade mais madura, naquelas que tiveram relações sexuais mais precoce, em fumantes do que não fumantes e nas mulheres promiscuas do que naquelas com um só parceiro (Rawls e col. ${ }^{21}$, 1986; Peto ${ }^{19}$, 1986; Doll ${ }^{7}, 1986$; Brinton e col. ${ }^{3}, 1986$ ).

Vários desses achados sugerem a hipótese de que 0 câncer cervical está relacionado com algum aspecto da atividade sexual, ou mais precisamente, que seria causado por um ou mais fatores venéreos. O pico da incidência do carcinoma "in situ" 20-30 anos mais cedo do que o câncer invasivo, também sugere a presença de um ou mais fatores venéreos começando sua ação no início da atividade sexual. Isto poderia sugerir também que a mucosa cervical seria mais susceptível a um possivel agente em jovens do que em idades mais maduras (Shingleton e $\mathrm{Orr}^{23}, 1987$ ).

Existem, no entanto, outros dados - tais como a variação entre populações ao longo do tempo - que 
poderiam sugerir a existência de outros fatores etiológicos ou promotores, relacionados com a nutrição ou higiene.

Nos últimos anos, tem havido um crescente esforço para avaliar o papel de algum vírus na etiologia do câncer cervical. O HSV (vírus herpes simples) foi o primeiro a ser avaliado, mas Petol9 (1986), Brinton $^{2}$ (1986) e Doll ${ }^{7}$ (1986) relataram que os estudos epidemiológicos mais cuidadosos não encontraram associação en tre o câncer cervical com oHVS 1 ou 2.

Por outro lado, substanciais evidências têm sido acumuladas, durante os últimos anos, implicando o HPV (vírus papiloma humano), como um agente etiológico do câncer cervical.

Estudo levado a cabo por Syrjanen e col.25 (1981) mostrou que em 48 mulheres com infecção por HPV, 10,6\% progrediram para carcinoma "in situ", dentro do período de 20 meses. A taxa mais alta de progressão foi associada com o HPV $16(45,5 \%)$, enquanto o HPV 18 mostrou uma taxa de $27 \%$. Peto $^{19}$ (1986) afirmou claramente que a questão a ser respondida epidemiologicamente seria se tipos particulares de HPV são mais relacionados com alteraçōes neoplásicas ou pré-neoplásicas, do que outros tipos seriam. O próprio autor responde a questão dizendo que existe um potencial oncogênico diferente entre o HPV de tipo 6 e 11, os quais são mais comumente observados em condilomas cervicais, enquanto que o HPV tipo 16 é mais comumente encontrado em lesర̃es pré-invasivas ou invasivas.

Planner e Hobbs ${ }^{20}$ (1987) encontraram neoplasia intraepitelial cervical (NIC) em 94 entre 333 pacientes biopsiadas (28\%), as quais tinham tido HPV previamente detectadas por citologia. Também Lorincz e col. ${ }^{15}$ (1987) relataram que $77 \%$ das NIC biopsiadas tinham mostrado presença do HPV, especialmente dos tipos 16 e18. A Figura 8 mostra os achados desses autores, podendo-se notar que a proporção de HPV encontrada, aumenta com a gravidade dos achados histológicos. Fuchs e col. ${ }^{9},(1988)$ relataram que o HPV 16 é claramente mais abundante do que outros tipos nas neoplasias intraepiteliais cervicais severas e nos cânceres invasivos.

A despeito de concordarem que os vírus papiloma humano dos tipos 16 e 18 estão associados com um risco mais elevado de ncoplasia cervical, Muñoz e col. ${ }^{17}$. (1988) advertem que vários dos estudos publicados são difíceis de interpretar e não satisfazem os requerimentos epidemiológicos básicos. Especificamente, cles citam que são desconhecidas a especificidade e a sensibilidade de vários métodos diagnósticos da tipologia do HPV.

\section{Fatores de Risco}

A análise dos fatores de risco é uma das armas

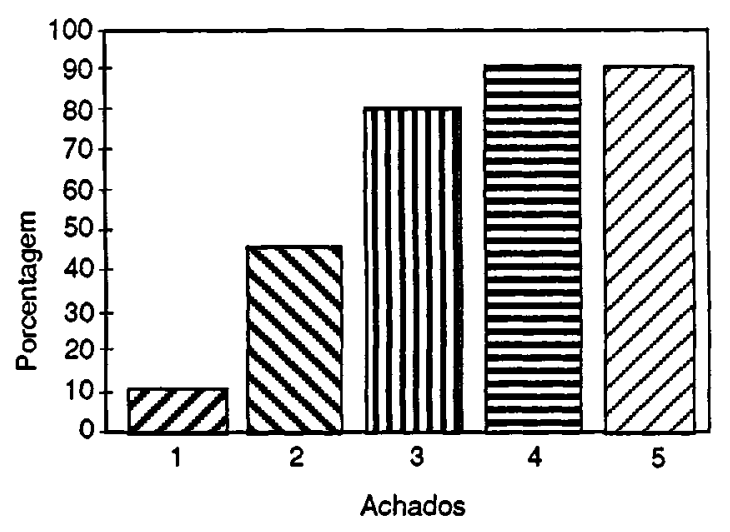

1 - Epitélio escamoso normal

2 - Epitélio escamoso metaplásico

3. Carcinoma "in situ"

4. Carcinoma epidermóide invasivo

5 - Adenocarcinoma endocervical

Figura 8. Porcentagem de seqüência viral através da hibridização molecular em 190 biópsias do colo uterino. Fonte: World Health Organization ${ }^{28}$

mais poderosas que a epidemiologia fornece para uma avaliação das hipóteses relativas à etiologia das doenças. Estudos posteriores podem ou não estabeleccr a validade de tais hipóteses.

\section{Comportamento Sexual}

Fatores tais como: relacionamento sexual precoce, casamento em idade muito jovem, idade jovem na primeira gravidez, parceiros sexuais múltiplos e múltiplos casamentos são - em nossa opinião - as maneiras que um agente venéreo, provavelmente o HPV, poderia entrar em contato com a mucosa cervical. E evidente, também, que todos estes fatores estão muito correlacionados e, assim, é necessária uma atenção especial para avaliar-se o papel dos fatores de confusão.

Harris e col. ${ }^{10}(1980)$, por exemplo, reportaram que o número de parceiros sexuais distingue-se como um fator independente da idade da primeira relação sexual. O risco relativo encontrado para jovens antes dos 17 anos foi de 1,55 se tivesse apenas um parceiro, crescendo para 7,53 , se tivesse 6 ou mais parceiros. Os mesmos autores também relataram que os fatores de risco identificados para o carcinoma "in situ" foram similares para aqueles identificados para o câncer invasivo, dando suporte às hipóteses de que ambos fazem parte de um "continuum".

Os mesmos achados relativos à idade ao primeiro coito e número de parceiros sexuais, foram encontrados por Rawls e col. ${ }^{21}$ (1986). Estes 
autores apoiam a idéia de que a parceria sexual múltipla aumentaria a probabilidade de exposição a um agente transmitido sexualmente, enquanto que a idade precoce ao primeiro coito poderia significar a presença de um epitélio cervical puberal mais susceptivel à agressão oncogênica. Estes autores também relataram um risco relativo de 1,45 em mulheres com 2 ou mais casamentos e de 1,38 para mulheres que tiveram o primeiro casamento ou gravidez antes dos 20 anos de idade.

Kessler $^{13}$ (1986) acredita que as variáveis sócio culturais, tais como raça, educação e status econômico, estão - com grande probabilidade - secundariamente relacionados a agente transmitido sexualmente.

Brinton $^{2}$ (1986) publicou estudo tipo casocontrole sobre o câncer invasivo do colo uterino, em 5 áreas geográficas dos Estados Unidos e usando modelos logísticos multivariados - obteve os fatores de risco após controlar os fatores de confusão. Em relação à exposição sexual, ela encontrou um risco linearmente crescente com o número de parceiros sexuais, chegando a uma razão de risco ajustado de 2,51 para mulheres com 5 ou mais parceiros, comparadas com aquelas que relataram apenas um parceiro sexual. Apesar da idade na primeira relação ter sido parcialmente confundida com o número de parceiros sexuais, permaneceu um efeito residual deste fator, com uma razão de risco ajustada de 2,27.

Estas ligações entre o câncer cervical com a prática sexual levaram um certo número de investigadores a especular não apenas sobre a possibilidade da etiologia viral desta neoplasia, mas também que o comportamento sexual feminino seria a única causa da exposição ao vírus. Entretanto - em nossa opinião - apenas o comportamento sexual feminino falha em explicar várias características do câncer cervical. Como, por exemplo, explicar a alta incidência na América Latina, onde em muitos paises a virgindade antes do casamento e a fidelidade dentro do casamento são muito mais valorizados do que em muitos países desenvolvidos?

Starreveld e col. ${ }^{24}$ (1983) relataram que em paises desenvolvidos ocorre incremento do número de adolescentes sexualmente ativos (de $17 \%$ em adolescentes com 13 anos a $67 \%$ naquelas com 18 anos de idade). Ainda, Sadeghi e col. ${ }^{22}$ (1984) reportaram que pelo menos $50 \%$ das ado. lescentes sexualmente ativas nos Estados Unidos têm parceiros múltiplos.

Assim, o grande declínio na incidência desta neoplasia em vários países ocidentais parece algo contraditório, levando-se em conta os achados acima descritos. Também, parece improvável que as mulheres em geral, estejam tendo, progressivamente, menos parceiros sexuais ao longo do tempo.
Paul e col. ${ }^{18}$ (1982), sugerem que estas contradições podem ser explicadas, levando-se em conta o comportamento sexual da sociedade como um todo, particularmente, os hábitos sexuais do homem. Assim, se o câncer cervical é causado por um agente infeccioso transmitido sexualmente, os antecedentes sexuais do parceiro masculino devem ser de grande importância. Os autores sugerem três tipos de sociedade: no tipo A, ambos, homens e mulheres, são fortemente desencorajados de ter relaçðes extra-conjugais. No tipo $B$, espera-se das mulheres apenas um parceiro sexual, enquanto dos homens - muitas vezes - espera-se que tenham várias parceiras, como na América Latina. Nesse caso, também é muito comum a prostituição. No tipo C, ambos, homens e mulheres, tendem a ter vários parceiros sexuais durante suas vidas. Este pode ser o padrão de vários países desenvolvidos do Ocidente. Além do mais, Paul e col. ${ }^{18}$ citam Alzate, que tinha estudado o comportamento sexual na Colômbia, relatando que apenas $34 \%$ das mulheres tinham relações sexuais pré-maritais. Inversamente, $91 \%$ dos homens relataram relacionamentos prévios, e destes, $92 \%$ tiveram contatos com prostitutas.

Desta forma, a hipótese que a infecção peniana pelo HPV é importante na exposição das mulheres ao risco do câncer cervical, vem crescendo gradualmente. Clarkson e col. ${ }^{5}$ (1985) encontraram que, de 25 mulheres parceiras de homens com condiloma acuminado no pênis, 9 (36\%) tiveram diagnósticos como tendo neoplasia intraepitelial cervical, comparadas com nenhuma das $20 \mathrm{mu}$ lheres do grupo de controle.

Villa e Lopes ${ }^{27}$ (1986) observaram que as taxas de câncer peniano em Recife aparecem como uma das incidências mais altas do mundo $(6,8 / 100.000$ habitantes), concordando com a alta incidência de câncer cervical na mesma cidade. Os mesmos autores relataram que o HPV tipos 16 e 18 mostram uma forte associação com os tumores malignos do pênis.

\section{Tabagismo}

Um importante aspecto no estudo das possiveis influências do tabagismo no câncer cervical, é a avaliação de vários fatores de confusão, especialmente comportamento sexual e classe social.

Clarke e col. ${ }^{4}$ (1982) relataram um risco relativo de 2,3 para o câncer cervical invasivo em fumantes e de 1,7 para ex-fumantes, controlando para classe social e para idade ao primeiro coito. $O$ número de parceiros sexuais não foi controlado.

Brinton e col. ${ }^{2}$ (1986), conduziram um estudo caso-controle em 480 mulheres com câncer cervical tipo epidermóide e 797 controles. Após um ajusta- 
mento para idade ao primeiro coito e número de parceiros sexuais, foi observado uma razão de risco de 1,5 com a história de tabagismo. Além do mais, os autores verificaram uma relação linear significativa entre o número de cigarros fumados por dia e anos de tabagismo, com o câncer do colo uterino.

Numa extensa revisão, Vessey ${ }^{26}$ (1986) relata que o tabagismo aumenta o risco do câncer cervical, independente de outros fatores.

Brinton $^{2}$ (1986) sugere duas principais hipóteses para possíveis mecanismos biológicos que poderiam estar relacionados com o fumo e o câncer cervical: um seria o efeito carcinogênico de substâncias provindas do cigarro e excretadas no muco cervical, e o outro seria possiviveis efeitos imunosupressivos.

Hellberg e col. ${ }^{12}$ (1988) analisaram os níveis de nicotina e cotinina no sangue e compararam com os níveis no muco cervical de pacientes com neoplasia intraepitelial cervical e concluíram que a cotinina, e especialmente a nicotina, apresentavamse em níveis muito mais alto no muco cervical do que no plasma sanguiíneo.

McArdle e Muller ${ }^{16}$ (1986) sugeriram que haveria uma diminuição da vigilância imunitária local, baseada na densidade das células de Langerhan encontradas nos condilomas viróticos e na neoplasia intraepitelial cervical.

Barton e col. ${ }^{1}$ (1988) também relataram que o tabagismo está associado com um decréscimo significativo na população de células de Langerhan, tanto no epilélio normal quanto em lesões neoplásicas intraepiteliais cervicais. Esses autores também encontraram uma relação dose-resposta, entre o número de cigarros fumados diariamente $\mathrm{e}$ o número de células de Langerhan encontradas.

\section{Contracepção}

Os estudos delineados para estudar o papel dos hábitos contraceptivos no risco de neoplasia do colo, precisam levar em conta os seguintes fatores de confusão:

- comportamento sexual

- a possibilidade do grupo controle estar usando métodos de barreira

- o rastreamento mais freqüente das usuárias de pîlula.

Um dos primeiros estudos sobre contracepção hormonal foi efetuado por Harris e col. ${ }^{10}$ (1980), os quais observaram um risco relativo de 2,1 para carcinoma "in situ" e displasia, em pacientes usando pílulas por 10 anos ou mais, controlando pelos fatores: idade à primeira relação e número de parceiros sexuais. O relatório da $W^{2} H^{29}$ (1985) foi outro a mostrar que o uso de pílula, por tempo prolongado, pode aumentar o risco de câncer invasi- vo, também controlando pelos fatores sexuais.

Brinton ${ }^{2}$ (1986), depois de fazer ajustamento para os devidos fatores de confusão, relatou uma inclinação linear significativa do risco, com relação à duração do uso da pilula. Entre usuárias por tempo prolongado (10 anos ou mais), o risco rclativo encontrado foi de 1,84 .

$\mathrm{O}$ mecanismo sugerido pelo estudo da WHO para explicar o risco aumentado - é que o efeito progestacional da pílula poderia suprimir o processo de maturação normal do epitélio cervical, o qual poderia tornar-se mais susceptivel a agentes sexualmente transmissíveis, que poderiam causar o câncer do colo uterino.

Por outro lado, a proteção contra infecções sexualmente transmissíveis é um efeito benéfico importante do diafragma, condom e espermicidas, As propriedades anti-virais do espermicida, e também a barrcira mecânica para a transmissão virótica, podem ser responsáveis pelo baixo risco de displasia e câncer cervical, observado em casais que usam métodos de barreira (Hatcher ${ }^{11}$, 1988). Feldblum e Fortney ${ }^{8}$ (1988), baseados em estudos "in vitro", relataram que o HIV (vírus da imunodeficiência humana), não pode passar através o latex. O HIV tem aproximadamente 120 nanômetros de. diâmetro, enquanto que o HPV tem cerca de 55 .

\section{Outros Fatores}

Outros fatores, especialmente a dieta, educação, higiene e infecções genitais inespecíficas, têm sido menos estudados do que os fatores previamente revisados. Entretanto, Cramer ${ }^{6}$ (1982) dcclarou - com muita propriedade - sua crença de que nenhum agente poderia ser considerado fator causativo único do câncer cervical.

LaVecchia e col. ${ }^{14}$ (1984) encontrou uma relação inversa do câncer cervical com o Beta Caroteno da dieta. $O$ risco relativo encontrado foi de 6,1 para aquelas pessoas enquadradas como de baixa ingestão, comparadas com aquelas com mais alta ingestão.

Brinton ${ }^{2}$ (1986) relatou que o nível educacional persiste como fator de risco - depois de controlado os outros fatores. As mulheres com educação equivalente ao segundo grau (secundário) mostraram um risco relativo de 0,5 , comparado com aquelas com apenas educação primária. Também foi observado um risco relativo de 2,1 , para mulheres com história de infecções genitais inespecíficas, após o controle para variáveis de confusão.

\section{Pesquisas Futuras}

Os estudos epidemiológicos têm conduzido a uma consistente associação entre o câncer cervical 
e o HPV. Entretanto, dados mais confiáveis são ainda necessários para avaliar as diferenças do câncer entre populaçōes, $a$ influência de possíveis co-fatores e as tendências da infecção do HPV em relação à idade.

Também é necessário uma avaliação mais precisa entre as diferenças em potencial oncogênico dos vários tipos do vírus, sobre a menor incidência dos cânceres do pênis, vagina e vulva, a despeito da proporção similar de HPV detectada nesses tumores e a estandardização dos métodos atuais de diagnóstico.

Outra possibilidade, sugerida por $\operatorname{Doll}^{7}(1986)$, seria um estudo coorte retrospectivo, entre material biopsiado ou mesmo de esfregaço, se dois ou mais resultados positivos fossem obtidos de cada paciente. $O$ material poderia ser examinado para verificar-se a presença de HPV, e efetuado, então, uma comparação entre os achados.

Desta maneira, existem diversas possibilidades e idéias a respeito do estudo do câncer cervical. Nossa esperança é que os futuros achados possam esclarecer não apenas os aspectos ligados à etiologia, mas também a possibilidade de novos caminhos para melhorar sua prevenção e tratamento.

ALEXXO NETO, A. [Epidemiological aspects of cervical cancer]. Rev. Saúde públ., S. Paulo, 25: 32633,1991 . A review concerning the epidemiological issues relating to cervical cancer, one of the most frequent in the women of developing countries, was undertaken in - Brazil, the incidence rate varies from $23.7 / 100,000$ in Porto Alegre to $83.2 / 100,000$ in Recife. In the United States, the 1978 incidence rate was $6.8 / 100,000$ in white women and 14.7/100,000 among black women. Several studies have suggested the hypotheses that cervical cancer could be related to some venereal agent. The evidences have shown the human papillomavirus (HPV) to be the main etiological agent. Several studies on the validity of such a hypotheses were realyzed and it became clear that there does infact exist a relationship between the HPV and cervical cancer. Finally, the better known risk factors, such as sexual behaviour, smoking and the contraception were studied in the light of the various etiological hypotheses.

Keywords: Cervix neoplasms, epidemiology. Papillomaviruses. Risk factors.

\section{Referências Bibliográficas}

1. BARTON, S.E.; MADDOX, P.H.; JENKINS, D.; EDWARDS, R.; CUZIK, J.; SINGER, A. Effect of cigarette smoking on cervical epithelial immunity: a mechanism for neoplastic change? Lancet, 2: 652-4, 1988.

2. BRINTON, L.A. Current epidemiological studies-emerging hypotheses. In: Peto, R. \& Hausen, H.Z. Viral etiology of Cancer. Cold Spring Harbor, N.Y., Cold Spring Harbor Laboratory, 1986.
3. BRINTON, L.A.; SCHAIRER, C.; HAENSZEL, W.; STOLLEY, P.; LEHMAN, H.F.; LEVINE, R.; SAVITZ, D.A. Cigarette smoking and invasive cervical cancer. $J$. Amer.med.ass., 255: 3265-9, 1986.

4. CLARKE, E.A.; MORGAN, R.W.; NEWMAN, A.M. Smoking as a risk factor in cancer of the cervix: additional evidence from a case control study. Amer. J. Epidem., 115: 59-62, 1982.

5. CLARKSON, P.K.; CAMPION, M.J.; SINGER, A. Increased risk of cervical neoplasia in consorts of men with penile condyloma acuminata. Lancet, 1: 943-6, 1985.

6. CRAMER, D.W. Uterine cervix. In: Schottenfeld, D. \& Fraumeni, J.F. Cancer epidemiology and prevention. Philadelphia, Saunders, 1982.

7. DOLL, R. Implications of epidemiological evidence for future progress. In: Peto, R., \& Hausen, H.Z. Viral etiolo. gy of cancer. Cold Spring Harbor, N.Y., Cold Spring Harbor Laboratory, 1986.

8. FELDBLUM, P.J. \& FORTNEY, J. Condoms, spermicides and the transmission of human immunodeficiency virus: a review of the literature. Amer. J. publ. Hlth, 78: $52-4,1988$.

9. FUCHS, P.G.; GIRARDI, F.; PFISTER, H. Human papillomavinus DNA in nomal, metaplastic, preneoplastic and neoplastic - epithelis of the cervix uteri. Int.J. Cancer, $41: 41-5,1988$.

10. HARRIS, R.W.C. et al. Characteristics of women with dysplasis or carcinoma in situ of the cervix uteri. Brit. $J$. Cancer, 42: 359-69, 1980.

11. HATCHER, R.A. et al. Contraceptive technology: 19881989. New York, Irvington Publisher, 1988.

12. HELLBERG, D.; NILSSOM, S.; HALEY, N.J.; HOFFMAN, D.; WYNDER, E. Smoking and cervical intraepithelial neoplasia: nicotine and cotinine in serum and cervical mucus in smokers and nonsmokers. Amer. $J$. Obstet. Gynec., 158: 910-3, 1988.

13. KESSLER, I.I. Cervical cancer: social correlates. In: Peto, R. \& Hausen, H.Z. Viral etiology of cancer. Cold Spring Harbor, N.Y., Cold Spring Harbor Laboratory, 1986.

14. LAVECCHIA, C.A. et al Dietary vitamin A and risk of invasive cervical cancer. Int. J. Cancer, 34: 319-24, 1984.

15. LORINCZ, A.T.; TEMPLE, G.F.; KURMAN, R.J.; JENSON, A.B.; LANCASTER, W.D. Oncogenic association of specific human papillomavirus types with cervical neoplasia. J. Nat. Cancer Inst.; 79: 671-7, 1987.

16. MCARDLE J.P. \& MULLER, H.K. Quantitative assessment of Langerhans'cells in human cervical intraepithelial neoplasis and Wart virus infection. Amer.J. Obstet. Gynec, 154: 509-15, 1986.

17. MUÑOZ, N.; BOSCH, X.; KALDOR, J.M. Does human papillomavirus cause cervical cancer? The state of the epidemiological evidence.Brit.J.Cancer, 57: 1-5, 1988.

18. PAUL, C.; SKEGG, D.C.G.; CORWIN, P.A. Importance of the male factor in cancer of the cervix. Lancet, 1: 581$3,1982$.

19. PETO, R. Introduction: geographic patterns and trends. In: Peto, R. \& Hausen, H.Z. Viral etiology of cancer. Cold Spring Harbor, N.Y., Cold Spring Harbor Laboratory, 1986.

20. PLANNER, R.S. \& HOBBS, J.B. Human Papilloma virus infection and associated intraepithelial neoplasia of the cervix, vagina and vulva. Aust. NZ. J. Obstet. Gynaec., 27: 132-5, 1987.

21. RAWLS, W. E. et al. Comparison of risk factors for cervical cancer in different populations.Int. J. Cancer, 37: $537.46,1986$.

22. SADEGHI, S.B.; HSIEH, E.W.; GUNN, S.W. Prevalence of cervical intraepithelial neoplasia in sexually active tcenagers and young adults: results of data analysis of 
mass Papanicolaou screening of 796,337 women in the United States in 1981. Amer. J. Obstet. Gynec., 148: 726-9, 1984.

23. SHINGLETON, H.M. \& ORR, J.W. Cancer of the cervix: diagnosis and treatment. New York, Churchill Livingstone, 1987.

24. STARREVELD, A.A.; ROMANOWSKI, B.; HILL, G.B.; $\mathrm{KOCH}, \mathrm{M}$;; PEARCE, K.I. The latency period of carcinoma-in-situ of the cervix. Obstet. Gynec., 62: 348-52, 1983.

25. SYRJANEN, K.J.; HEINONEN, U.M.; KAVRANIEMI, T. Cytologycal evidence of the association of condylomatous lesions with the displastic and neoplastic changes in uterine cervix. Acta cytol., 25: 17-21, 1981.

26. VESSEY, M.P. Epidemiology of 'cervical cancer: role of hormonal factors, cigarette smoking and occupation. In: Peto, R. \& Hausen, H.Z. Viral etiology of cancer. Cold
Spring Harbor, N.Y., Cold Spring Harbor Laboratory, 1986.

27. VILLA, L.L. \& LOPES, A. Human Papillomavirus DNA sequences in penile carcinomas in Brazil. Int. J. Cancer, 37: 853-5, 1986.

28. WORLD HEALTH ORGANIZATTON. The cancer incidence in five continents. Lyon, Intemational Agency for Research on Cancer, 1972, 1982, 1987. v. 3-5.

29. WORLD HEALTH ORGANIZATION. Collaborative Study of Neoplasma and Steroid Contraceptives. Invasive cervical cancer and combined oral contraceptives. Brit.med. J., 290: 961-5, 1985.

Recebido para publicaçäo em 28/11/1990 Aprovado para publicação em 29/04/1991 